Research Article

\title{
Thermophysical Properties of 1-Octyl-3-Methylimidazolium Acetate with Organic Solvents
}

\author{
Fuxin Yang $(D)$ and Peng Feng $(i D$ \\ Key Laboratory of Thermo-Fluid Science and Engineering, Ministry of Education, Xi'an Jiaotong University, Xi'an, \\ Shaanxi 710049, China \\ Correspondence should be addressed to Fuxin Yang; fxyang@xjtu.edu.cn
}

Received 14 October 2020; Revised 9 November 2020; Accepted 1 December 2020; Published 9 December 2020

Academic Editor: Ho SoonMin

Copyright ( 92020 Fuxin Yang and Peng Feng. This is an open access article distributed under the Creative Commons Attribution License, which permits unrestricted use, distribution, and reproduction in any medium, provided the original work is properly cited.

\begin{abstract}
Ionic liquid (IL) usually possesses high viscosity. In this work, the selected organic solvents, namely, dimethyl sulfoxide, N,Ndimethylacetamide, and N,N-dimethylformamide, were used as the diluents to lower IL viscosity. The thermophysical properties of the densities and viscosities for the binary mixtures of IL (i.e., 1-octyl-3-methylimidazolium acetate) with solvents were studied at normal pressure in the temperature ranges of $303.15 \mathrm{~K}$ to $348.15 \mathrm{~K}$. The effects of the organic solvents on lowering IL viscosity were quantitatively evaluated. The excess properties of the mixtures were calculated to analyze the interactions between IL and solvents. The hard-sphere model was employed to reproduce the viscosity behavior of the pure substances and binary mixtures.
\end{abstract}

\section{Introduction}

Ionic liquids (ILs) are considered as the novel class of molten salts. They consist of the organic cations and organic anions or inorganic anions. The different anion and cation can be combined and synthetized as the new ionic liquid to meet the requirements for the application. Because of the tunable characteristics, there are huge ionic liquids to be explored. Moreover, due to their promising properties, such as the thermal stability, the good conducting nature, and the negligible vapor pressure, ILs are recognized as the green and environmentally friendly solvents, receiving extensive studies [1-3].

The imidazolium-based ILs, such as 1-alkyl-3-methylimidazolium chloride and 1-alkyl-3-methylimidazolium acetate, have been studied in the biofuel process and shown the ability to dissolve the lignocellulosic biomass [4]. Yang et al. and Wang et al. studied the oxidation cleavage of $\beta$-O-4 bond in lignin model compounds and lignin dissolution using the IL of 1-octyl-3-methylimidazolium acetate $\left(\left[\mathrm{C}_{8} \mathrm{mim}\right][\mathrm{OAc}]\right)[5,6]$. Zhang et al. reported the effect of the cation and anion structure of ionic liquids on the solubility of cellulose; however, $\left[\mathrm{C}_{8} \mathrm{mim}\right][\mathrm{OAc}]$ exhibited poor dissolving capability due to its high viscosity that impedes the cellulose dissolution in ILs [7]. One of the possible ways to reduce the effects of IL high viscosity is to use solvent as the diluent or additive into IL. Dimethyl sulfoxide (DMSO) is considered as the alternative solvent and the IL-DMSO mixture has been conducted in the biofuel production and biomass depolymerization [8]. The aprotic solvents of N,Ndimethylacetamide (DMA) and N,N-dimethylformamide (DMF) are also well studied [9]. Furthermore, publications have been focused on the influences of organic solvents on the properties of the binary mixtures containing IL with solvents $[10,11]$. The thermophysical properties, namely, the density and the viscosity, are the fundamental data for the scientific research and the industrial application, especially for industrial process design.

In this work, the viscosities and densities of 1-octyl-3methylimidazolium acetate together with the three organic solvents of DMSO, DMA, and DMF were conducted at atmospheric pressure $(0.0967 \pm 0.0020) \mathrm{MPa}$ from $303.15 \mathrm{~K}$ to $348.15 \mathrm{~K}$. The properties of $\left[\mathrm{C}_{8} \mathrm{mim}\right][\mathrm{OAc}]$ with $\mathrm{DMF}$ were not reported in the published studies as well as the binary mixture of $\left[\mathrm{C}_{8} \mathrm{mim}\right][\mathrm{OAc}]$ with DMSO and DMF in IL mole fraction from 0.1 to 1 . The viscosity and density of 
the pure substances and IL with solvents were measured using a capillary viscometer and an Anton-Paar vibrating U-tube densimeter, respectively. The effects of solvents on IL thermophysical properties were quantitatively studied. The excess properties of the mixtures were calculated for analyzing the interactions between ionic liquid with the solvents. The hard-sphere model was employed to reproduce the viscosity.

\section{Materials and Methods}

2.1. Materials. IL of 1-octyl-3-methylimidazolium acetate was supplied by Shanghai Weiting Reagent Biological Technology Co., Ltd. The organic solvents were obtained from Aladdin Shanghai Biochemical Technology Co., Ltd. The solvents were used in the experiment measurement without further treatment. IL was treated using the molecular sieves (3A, $1.6 \mathrm{~mm}$ pellets) obtained from SigmaAldrich (St Louis, MO). More details about the solvents and IL are summarized in Table 1. The chemical structure and physical properties of IL are listed in Table S1 (in the Supplementary Material).

2.2. Sample Treatment. The water content in ionic liquid is considered as the impurity and it would obviously affect the thermophysical properties of IL, especially of viscosity. To eliminate the influences, water was extracted from IL using the molecular sieves. The sieves were rinsed by acetone and methanol. The clean sieves were then put into an oven at $473.15 \mathrm{~K}$ for more than 8 hours. IL was mixed with the treated molecular sieves and they were placed in a vacuum at $353.15 \mathrm{~K}$ with the pressure of less than $2 \mathrm{kPa}$ for 48 hours. The mixtures of ionic liquid with solvents were weighed using a balance (ME204, Mettler Toledo) and its uncertainty was $0.0001 \mathrm{~g}$. The water content in the sample was detected by a moisture titrator (Kyoto Electronics Manufacturing Co., Ltd.) with less than 0.3 wt. \%.

2.3. Thermophysical Properties Measurement. The density was measured using an Anton-Paar vibrating $U$-tube densimeter $(5000 \mathrm{M})$. The hot water and methanol were used to clean the densimeter. The uncertainty of temperature was $0.01 \mathrm{~K}$. The relative standard uncertainty of density was 0.005 . The density data was measured three times.

The viscosity was measured using an Ubbelohde viscometer (9721-R53, 9721-R56, 9721-R59, 9721-R65, and 9721-R71) supplied by Cannon Instrument Company (Pennsylvania, USA). An immersion thermostat (LAUDA ECO Silver) was used to control an oil bath for the capillary cell and the temperature uncertainty was $0.01 \mathrm{~K}$. The flow time was determined by a stopwatch. The dynamic viscosity $\eta$ was calculated as follows:

$$
\eta=k t \rho
$$

where $k$ is the viscometer constant and it is determined using the standard solution, $t$ is the efflux time of the sample, and $\rho$ is the density corresponding to the same measurement condition.
The efflux time of the sample was more than $100 \mathrm{~s}$ and, the diameter of the capillary was $0.47 \mathrm{~mm}$ that was less than the length of $290 \mathrm{~mm}$; therefore, in the experiment, the kinetic energy was ignored as well as the end correction. Moreover, because the value of IL viscosity is always large, the Ubbelohde capillary with large viscometer constant was used for IL measurement (9721-R65 and 9721-R71), while the Ubbelohde capillary with small viscometer constant was performed for the organic solvents (9721-R53). The relative combined standard uncertainty of the viscosity in the measurement was 0.06 . The viscosities were measured three times.

In Table 2, the experimental densities and viscosities data in this work as well as the literature values at atmospheric pressure are presented to check the apparatus and the chemicals [12-21]. It is found that the densities and viscosities agree well with the literature values.

\section{Results and Discussion}

3.1. Experimental Density Data. In general, the experimental density data can be fitted as a linear equation:

$$
\rho=a+b \cdot T
$$

where $\rho$ is the density data in $\mathrm{kg} \cdot \mathrm{m}^{-3}$, the fitted parameters of $a\left(\mathrm{~kg} \cdot \mathrm{m}^{-3}\right)$ and $b\left(\mathrm{~kg} \cdot \mathrm{m}^{-3} \mathrm{~K}^{-1}\right)$ are correlated using the experimental density, and $T(\mathrm{~K})$ is the measurement temperature.

To check the deviation between the literature data and the experimental value, the average absolute relative deviation (AARD) is calculated as follows:

$$
\operatorname{AARD}(\%)=\frac{100}{n} \sum_{i=1}^{n}\left|\frac{E_{(\exp / \text { lit }), \mathrm{i}}-C_{\text {cal,i, }}}{E_{(\exp / \mathrm{lit}), \mathrm{i}}}\right|,
$$

where $n$ is the data points, $E_{\text {exp/lit,i }}$ is the experiment/literature value, and $C_{\mathrm{cal}, \mathrm{i}}$ represents the calculated data.

Table S2 gives the parameters for (2). The calculated density data of the three solvents are compared with those in the literature, as shown in Figures S1-S3 (in the Supplementary Material). The AARD is $0.04 \%$ for DMSO [12, 14, 22-26], 0.28\% for DMA [27-34], and 0.05\% for DMF $[14,20,27,28,35-38]$. The deviations between the literature data and the experiment values in this study are small. Therefore, the density data for the mixtures of ionic liquid with solvents are measured and summarized in Tables 3-5.

Figure 1 and Figures S4-S6 give the density as a function of temperature. It is found that the data increase with the decrease of the temperature. Generally, the temperature will affect the kinetic energy of the atom and the molecule. When the temperature increases, the kinetic energy increases as well as the volume of the substance; then the density decreases accordingly. In Figure 1, the values of densities can be ordered as follows: DMSO $>$ IL $>$ DMF $>$ DMA. Among these chemicals, the curve of DMSO is the sharpest. IL presents the less sharp curve and the absolute value of IL slope is the smallest.

In the density measurement of binary mixture, the excess molar volume is introduced to study the consistency of the 
TABLE 1: The descriptions of ionic liquid and organic solvents.

\begin{tabular}{lcccc}
\hline IL/solvent & Abbreviation & $\begin{array}{c}\text { Initial mass } \\
\text { fraction purity }\end{array}$ & Treatment & Source \\
\hline $\begin{array}{l}\text { 1-Octyl-3- } \\
\text { methylimidazolium acetate }\end{array}$ & $\begin{array}{c}{\left[\mathrm{C}_{8} \mathrm{mim}\right]} \\
{[\mathrm{OAc}]}\end{array}$ & $\geq 0.98$ & $\begin{array}{c}\text { Dry using } \\
\text { molecular sieve }\end{array}$ & $\begin{array}{c}\text { Shanghai Weiting Reagent Biological } \\
\text { Technology Co., Ltd. }\end{array}$ \\
$\begin{array}{l}\text { Dimethyl sulfoxide } \\
\text { N,N-dimethylacetamide }\end{array}$ & DMSO & $\geq 0.98$ & None & $\begin{array}{c}\text { Aladdin Shanghai Biochemical } \\
\text { Technology Co., Ltd. }\end{array}$ \\
N,N-dimethylformamide & DMA & $\geq 0.98$ & None & $-68-5$ \\
\hline
\end{tabular}

TABLE 2: Densities and viscosities of the pure chemicals at normal pressure $(0.0967 \pm 0.0020) \mathrm{MPa} *$.

\begin{tabular}{lccccc}
\hline \multirow{2}{*}{ IL/solvent } & \multicolumn{3}{c}{ Density $/ \mathrm{kg} \cdot \mathrm{m}^{-3}$} & \multicolumn{2}{c}{ Viscosity (mPa.s) } \\
& Temperature $(\mathrm{K})$ & This work & Literature & This work & Literature \\
\hline DMSO & 303.15 & 1090.4 & $1090.73[12], 1090.41[13]$ & 1.81 & $1.786[14], 1.84[15], 1.961[16]$ \\
DMA & 303.15 & 932.0 & $931.66[17], 931.69[13]$ & 0.88 & $0.8769[18], 0.87[19]$ \\
DMF & 303.15 & 939.7 & $939.34[17], 939.23[13]$ & 0.78 & $0.766[20], 0.7647[21]$ \\
\hline
\end{tabular}

${ }^{*}$ The standard uncertainty $(u)$ is $u(T)=0.01 \mathrm{~K}$. The relative standard uncertainty $\left(u_{\mathrm{r}}\right)$ is $u_{\mathrm{r}}(\rho)=0.005$. The relative combined standard uncertainty $\left(u_{\mathrm{c}, \mathrm{r}}\right)$ is $u_{c, r}(\eta)=0.06$.

TABLE 3: Experimental densities of [C8mim] [OAc] with organic solvent of DMSO at atmospheric pressure $(0.0967 \pm 0.0020) \mathrm{MPa}$ from $303.15 \mathrm{~K}$ to $348.15 \mathrm{~K}$.

\begin{tabular}{|c|c|c|c|c|c|c|c|c|c|}
\hline \multirow{3}{*}{$T / \mathrm{K}$} & \multicolumn{9}{|c|}{$x\left[\mathrm{C}_{8} \mathrm{mim}\right][\mathrm{OAc}]+(1-x) \mathrm{DMSO}, \rho / \mathrm{kg} \cdot \mathrm{m}^{-3}$} \\
\hline & \multicolumn{9}{|c|}{$x$} \\
\hline & 1.000 & 0.842 & 0.735 & 0.553 & 0.415 & 0.312 & 0.234 & 0.172 & 0.000 \\
\hline 303.15 & 988.8 & 994.5 & 999.6 & 1010.0 & 1020.8 & 1031.1 & 1041.0 & 1050.7 & 1090.4 \\
\hline 308.15 & 985.9 & 991.5 & 996.5 & 1006.7 & 1017.4 & 1027.5 & 1037.3 & 1046.7 & 1085.5 \\
\hline 313.15 & 982.9 & 988.4 & 993.3 & 1003.5 & 1014.0 & 1023.9 & 1033.5 & 1042.7 & 1080.5 \\
\hline 318.15 & 979.9 & 985.4 & 990.2 & 1000.2 & 1010.6 & 1020.4 & 1029.7 & 1038.8 & 1075.5 \\
\hline 323.15 & 976.9 & 982.3 & 987.1 & 997.0 & 1007.2 & 1016.8 & 1025.9 & 1034.8 & 1070.5 \\
\hline 328.15 & 973.9 & 979.3 & 984.0 & 993.8 & 1003.8 & 1013.2 & 1022.1 & 1030.8 & 1065.5 \\
\hline 333.15 & 970.9 & 976.2 & 980.9 & 990.5 & 1000.4 & 1009.6 & 1018.3 & 1026.8 & 1060.5 \\
\hline 338.15 & 967.9 & 973.1 & 977.8 & 987.3 & 997.0 & 1006.0 & 1014.5 & 1022.8 & 1055.5 \\
\hline 343.15 & 964.9 & 970.1 & 974.6 & 984.0 & 993.6 & 1002.4 & 1010.7 & 1018.8 & 1050.5 \\
\hline 348.15 & 961.9 & 967.1 & 971.5 & 980.8 & 990.2 & 998.8 & 1006.9 & 1014.7 & 1045.5 \\
\hline
\end{tabular}

The standard uncertainties $(u)$ are $u(x)=2.0 \cdot 10^{-3}$ and $u(T)=0.01 \mathrm{~K}$. The relative standard uncertainty $\left(u_{\mathrm{r}}\right)$ is $u_{\mathrm{r}}(\rho)=0.005$.

TABle 4: Experimental densities of [C8mim][OAc] with organic solvent of DMA at atmospheric pressure $(0.0967 \pm 0.0020)$ MPa from $303.15 \mathrm{~K}$ to $348.15 \mathrm{~K}$.

\begin{tabular}{|c|c|c|c|c|c|c|c|c|c|}
\hline \multirow{3}{*}{$T / \mathrm{K}$} & \multicolumn{9}{|c|}{$x\left[\mathrm{C}_{8} \mathrm{mim}\right][\mathrm{OAc}]+(1-x) \mathrm{DMA}, \rho / \mathrm{kg} \cdot \mathrm{m}^{-3}$} \\
\hline & \multicolumn{9}{|c|}{$x$} \\
\hline & 1.000 & 0.861 & 0.751 & 0.581 & 0.445 & 0.343 & 0.257 & 0.187 & 0.000 \\
\hline 303.15 & 988.8 & 986.1 & 983.7 & 978.9 & 973.3 & 967.8 & 961.9 & 955.8 & 932.0 \\
\hline 308.15 & 985.9 & 983.1 & 980.5 & 975.6 & 969.9 & 964.2 & 958.1 & 951.8 & 927.4 \\
\hline 313.15 & 982.9 & 980.0 & 977.4 & 972.3 & 966.4 & 960.5 & 954.3 & 947.8 & 922.8 \\
\hline 318.15 & 979.9 & 976.9 & 974.2 & 969.0 & 963.0 & 956.9 & 950.5 & 943.8 & 918.1 \\
\hline 323.15 & 976.9 & 973.8 & 971.1 & 965.7 & 959.5 & 953.3 & 946.7 & 939.8 & 913.5 \\
\hline 328.15 & 973.9 & 970.8 & 967.9 & 962.4 & 956.0 & 949.6 & 942.9 & 935.8 & 908.9 \\
\hline 333.15 & 970.9 & 967.7 & 964.8 & 959.1 & 952.5 & 946.0 & 939.1 & 931.5 & 904.2 \\
\hline 338.15 & 967.9 & 964.6 & 961.6 & 955.8 & 949.0 & 942.3 & 935.2 & 927.8 & 899.6 \\
\hline 343.15 & 964.9 & 961.6 & 958.5 & 952.5 & 945.5 & 938.7 & 931.4 & 923.8 & 894.9 \\
\hline 348.15 & 961.9 & 958.5 & 955.3 & 949.2 & 942.0 & 935.0 & 927.5 & 919.7 & 890.2 \\
\hline
\end{tabular}

The relative standard uncertainty $\left(u_{\mathrm{r}}\right)$ is $u_{\mathrm{r}}(\rho)=0.005$. 
TABLE 5: Experimental densities of [C8mim] [OAc] with organic solvent of DMF at atmospheric pressure $(0.0967 \pm 0.0020)$ MPa from $303.15 \mathrm{~K}$ to $348.15 \mathrm{~K}$.

\begin{tabular}{|c|c|c|c|c|c|c|c|c|c|}
\hline \multirow{3}{*}{$T / \mathrm{K}$} & \multicolumn{9}{|c|}{$x\left[\mathrm{C}_{8} \mathrm{mim}\right][\mathrm{OAc}]+(1-x) \mathrm{DMF}, \rho / \mathrm{kg} \cdot \mathrm{m}^{-3}$} \\
\hline & & & & & $x$ & & & & \\
\hline & 1.000 & 0.842 & 0.723 & 0.530 & 0.407 & 0.299 & 0.224 & 0.160 & 0.000 \\
\hline 303.15 & 988.8 & 986.7 & 984.7 & 980.1 & 975.8 & 970.8 & 966.1 & 960.6 & 939.7 \\
\hline 308.15 & 985.9 & 983.6 & 981.6 & 976.8 & 972.3 & 967.1 & 962.3 & 956.6 & 934.9 \\
\hline 313.15 & 982.9 & 980.5 & 978.4 & 973.4 & 968.8 & 963.4 & 958.4 & 952.6 & 930.1 \\
\hline 318.15 & 979.9 & 977.5 & 975.3 & 970.1 & 965.3 & 959.7 & 954.6 & 948.5 & 925.3 \\
\hline 323.15 & 976.9 & 974.4 & 972.1 & 966.7 & 961.8 & 956.0 & 950.7 & 944.4 & 920.5 \\
\hline 328.15 & 973.9 & 971.3 & 968.9 & 963.3 & 958.3 & 952.3 & 946.8 & 940.4 & 915.7 \\
\hline 333.15 & 970.9 & 968.2 & 965.7 & 960.0 & 954.8 & 948.6 & 942.9 & 936.3 & 910.9 \\
\hline 338.15 & 967.9 & 965.2 & 962.6 & 956.6 & 951.2 & 944.9 & 939.0 & 932.2 & 906.1 \\
\hline 343.15 & 964.9 & 962.1 & 959.4 & 953.2 & 947.7 & 941.1 & 935.0 & 928.1 & 901.2 \\
\hline 348.15 & 961.9 & 959.0 & 956.2 & 949.8 & 944.1 & 937.4 & 931.0 & 924.0 & 896.3 \\
\hline
\end{tabular}

The relative standard uncertainty $\left(u_{\mathrm{r}}\right)$ is $u_{\mathrm{r}}(\rho)=0.005$.

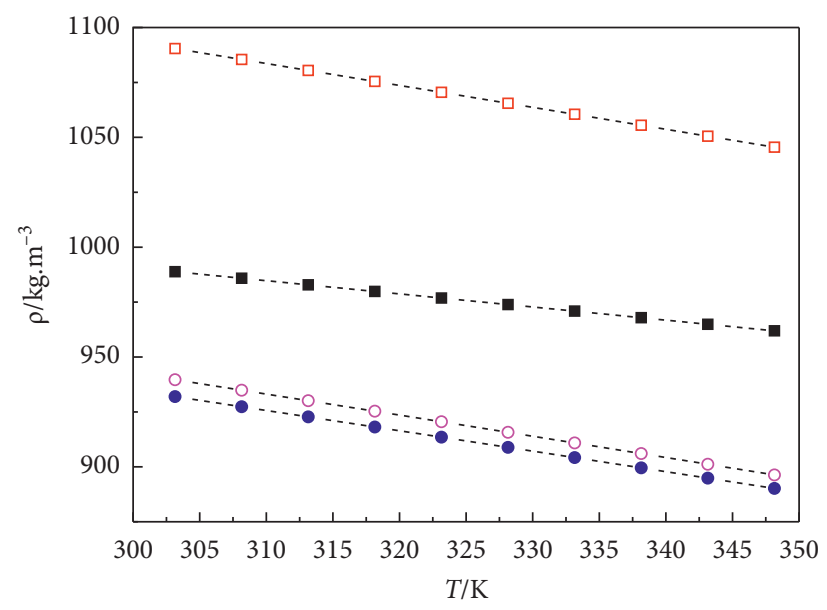

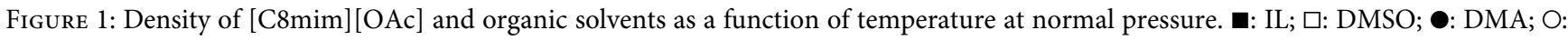
DMF. Dash line calculated by (2).

experiment density data [39]. The excess molar volume $V^{\mathrm{E}}$ is obtained by [40]

$$
\begin{aligned}
V^{E} & =V_{m}-\sum x_{i} V_{i}=\frac{\sum x_{i} M_{i}}{\rho_{m}}-\sum \frac{x_{i} M_{i}}{\rho_{i}} \\
& =\sum x_{i} M_{i}\left(\frac{1}{\rho_{m}}-\frac{1}{\rho_{i}}\right),
\end{aligned}
$$

where $V^{\mathrm{E}}$ is excess molar volume in $\mathrm{m}^{3} \cdot \mathrm{mol}^{-1}$. The subscripts of " $m$ " and " $i$ " mean the properties of mixture and pure substance $i$, respectively. $X$ is IL mole fraction. $V\left(\mathrm{~m}^{3} \cdot \mathrm{mol}^{-1}\right)$, $\rho\left(\mathrm{kg} \cdot \mathrm{m}^{-3}\right)$, and $M\left(\mathrm{~kg} \cdot \mathrm{mol}^{-1}\right)$ are the molar volume, density, and the molar mass, respectively. The combined standard uncertainty of excess molar volume is less than $2.24 \times 10^{-7} \mathrm{~m}^{3} \mathrm{~mol}^{-1}$.

The Redlich-Kister equation is introduced to fit excess molar volume [41, 42]:

$$
V^{E}=x(1-x) \sum_{i=0}^{n} A_{i}(2 x-1)^{i},
$$

where $x$ is IL mole fraction and $A_{\mathrm{i}}\left(\mathrm{m}^{3} \cdot \mathrm{mol}^{-1}\right)$ is the fit parameter correlated by experiment data in this work. Table S3 gives the fit parameters and AARD.

Figures 2-5 depict $V^{\mathrm{E}}$ as a function of IL mole fraction. The $V^{\mathrm{E}}$ values are negative, indicating that the volumes of mixtures become smaller than the ideal ones and there should be interactions between ionic liquid with solvents. In the previous studies, the negative $V^{\mathrm{E}}$ values were also observed for the mixture of 1-alkyl-3-methylimidazolium acetate with organic solvents, and the excess volume becomes more negative when the temperature increases $[43,44]$. The curves are asymmetric and the minimum values are detected in dilute regions.

Furthermore, Apelblat proposed a new two-parameter equation for correlation and prediction of densities as a 


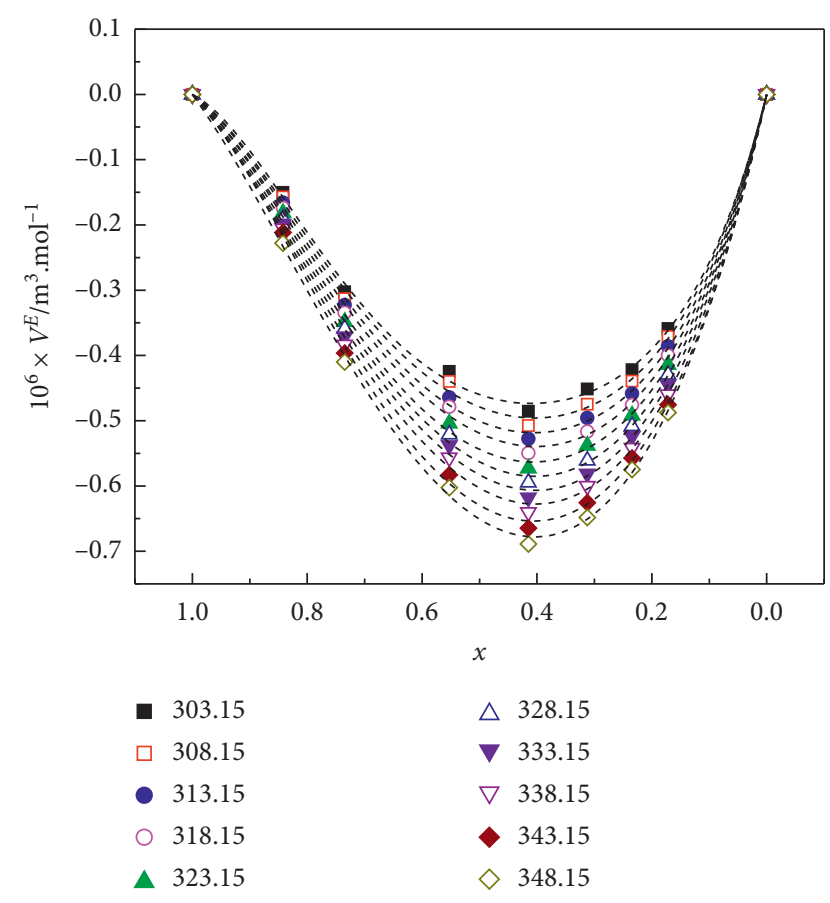

FIGURE 2: The excess molar volume of [C8mim] [OAc] with solvent of DMSO as a function of IL mole fraction at atmospheric pressure; dash line calculated by (5).

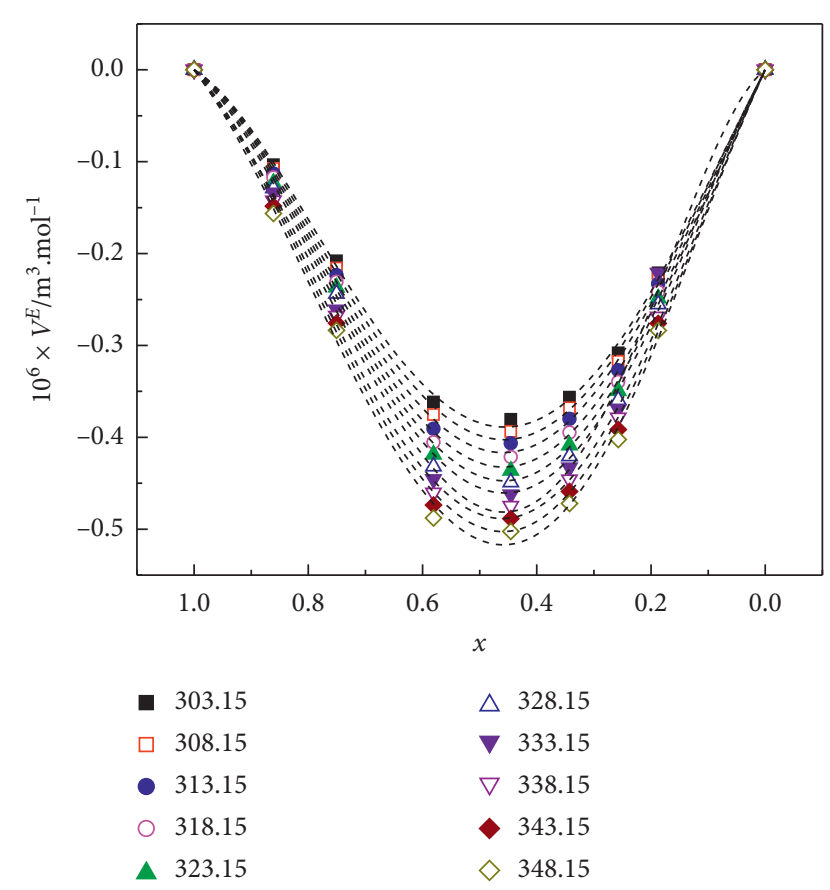

FIGURe 3: The excess molar volume of [C8mim] [OAc] with solvent of DMA as a function of IL mole fraction at atmospheric pressure; dash line calculated by (5).

function of temperature and concentration in binary aqueous solutions [45]. The equation is as follows:

$$
F(x)=\frac{1}{\rho_{\mathrm{IL}}(T)}-\frac{1}{\rho_{m}(T, x)} .
$$

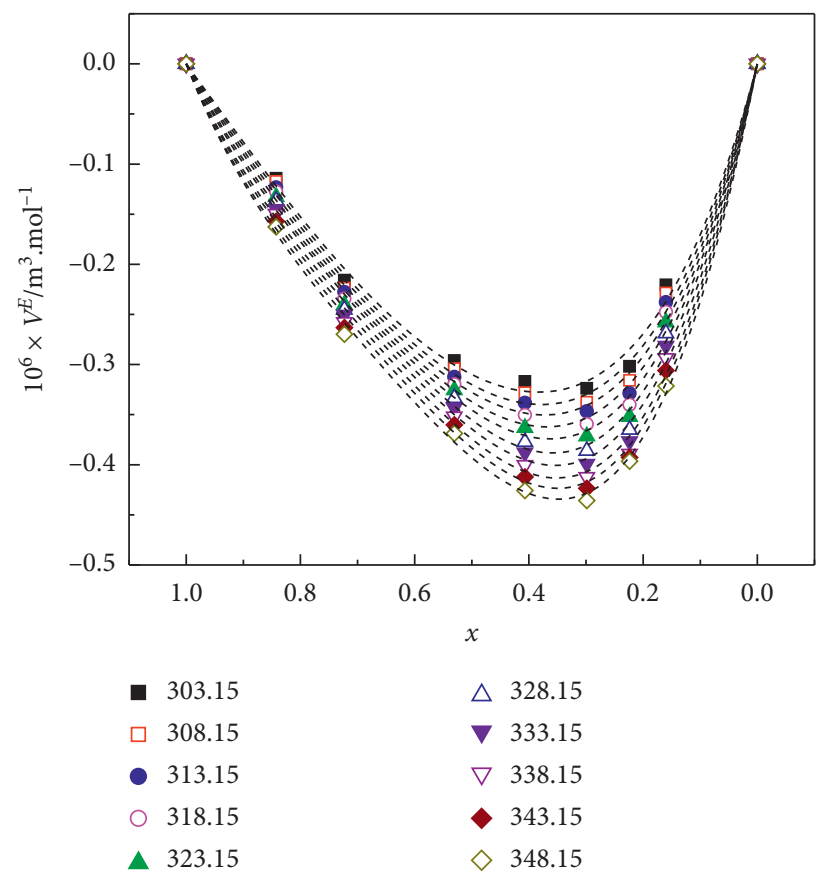

FIgURE 4: The excess molar volume of [C8mim] [OAc] with solvent of DMF as a function of IL mole fraction at atmospheric pressure; dash line calculated by (5).

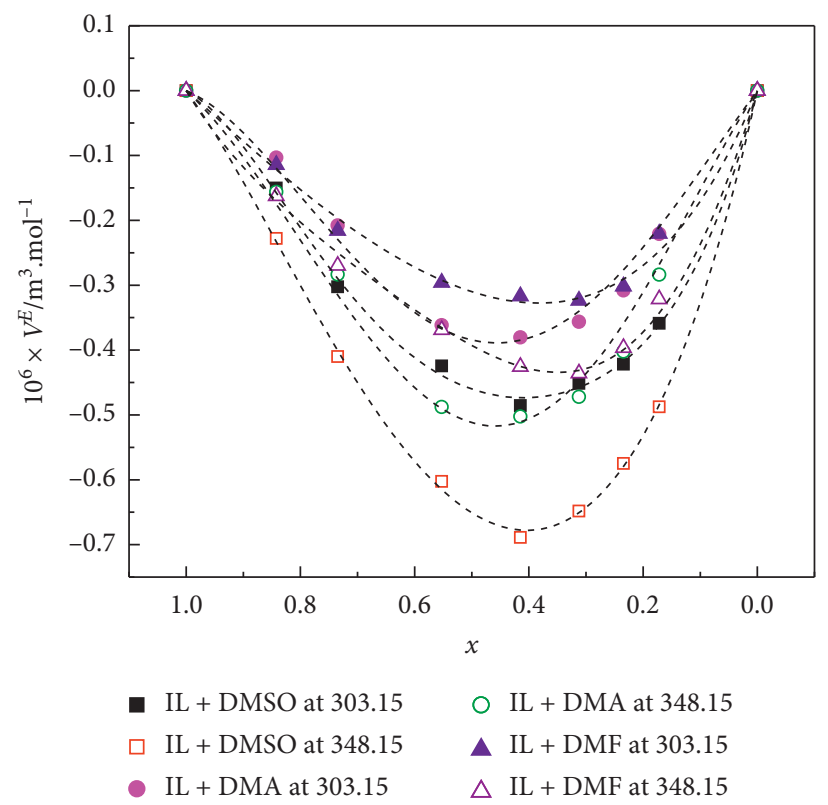

Figure 5: The excess molar volumes of [C8mim][OAc] with solvents as a function of IL mole fraction; dash line calculated by (5).

An expression of $F(x)=A x+B x^{2}$ was suggested; however, the errors were nonnegligible for the binary mixtures containing IL. In this work, a modified form was used:

$$
F(x)=C_{0}+C_{1} x+C_{2} x^{2}+C_{3} x^{3},
$$

where $\rho_{\mathrm{IL}}(T), \rho_{\mathrm{m}}(T, x)$ are the densities of IL and binary mixture, respectively. $X$ is the IL mole fraction. The 
TABLE 6: The parameters for (8), the average absolute relative deviations, and the energy barriers at $303.15 \mathrm{~K}$.

\begin{tabular}{|c|c|c|c|c|c|c|}
\hline$(1-x)$ solvent & $x \mathrm{IL}$ & $\eta_{0} / \mathrm{mPa} \cdot \mathrm{s}$ & $B / \mathrm{K}$ & $T_{0} / \mathrm{K}$ & AARD $/ \%$ & $E_{\eta}(303.15 \mathrm{~K}) / \mathrm{kJ} \cdot \mathrm{mol}^{-1}$ \\
\hline \multirow{9}{*}{ DMSO } & 1 & 0.0575 & 1129.78 & 171.38 & 0.46 & 49.72 \\
\hline & 0.842 & 0.0033 & 1912.17 & 126.05 & 1.43 & 46.59 \\
\hline & 0.735 & 0.1128 & 813.87 & 181.82 & 0.49 & 42.24 \\
\hline & 0.553 & 0.0013 & 2276.67 & 88.90 & 1.05 & 37.90 \\
\hline & 0.415 & 0.0789 & 823.74 & 161.75 & 1.33 & 31.48 \\
\hline & 0.312 & 0.1406 & 607.48 & 171.92 & 0.11 & 26.95 \\
\hline & 0.234 & 0.0030 & 1736.27 & 70.74 & 0.89 & 24.56 \\
\hline & 0.172 & 0.2490 & 249.14 & 203.96 & 0.59 & 19.35 \\
\hline & 0 & 0.0299 & 964.27 & 68.29 & 0.20 & 13.36 \\
\hline \multirow{8}{*}{ DMA } & 0.861 & 0.0030 & 1950.82 & 122.99 & 0.68 & 45.93 \\
\hline & 0.751 & 0.0362 & 1136.57 & 156.53 & 0.76 & 40.40 \\
\hline & 0.581 & 0.0915 & 842.54 & 169.93 & 1.21 & 36.27 \\
\hline & 0.445 & 0.1719 & 640.66 & 176.45 & 1.21 & 30.49 \\
\hline & 0.343 & 0.1668 & 547.88 & 176.39 & 0.83 & 26.05 \\
\hline & 0.257 & 0.0282 & 1092.06 & 92.89 & 0.60 & 18.87 \\
\hline & 0.187 & 0.2136 & 311.70 & 175.77 & 0.32 & 14.68 \\
\hline & 0 & 0.0504 & 632.35 & 82.11 & 0.14 & 9.89 \\
\hline \multirow{8}{*}{ DMF } & 0.842 & 0.0380 & 1227.37 & 155.39 & 0.49 & 42.96 \\
\hline & 0.723 & 0.0328 & 1139.00 & 157.09 & 1.37 & 40.80 \\
\hline & 0.530 & 0.0786 & 961.50 & 150.06 & 0.20 & 31.35 \\
\hline & 0.407 & 0.0896 & 784.93 & 158.19 & 0.28 & 28.54 \\
\hline & 0.299 & 0.0734 & 850.06 & 133.74 & 0.25 & 22.63 \\
\hline & 0.224 & 0.1019 & 594.21 & 129.85 & 0.97 & 15.12 \\
\hline & 0.160 & 0.0834 & 616.26 & 112.00 & 0.36 & 12.89 \\
\hline & 0 & 0.0996 & 328.56 & 142.97 & 0.28 & 9.78 \\
\hline
\end{tabular}

TABLE 7: Experimental viscosities of [C8mim] [OAc] with organic solvent of DMSO at atmospheric pressure $(0.0967 \pm 0.0020)$ MPa from $303.15 \mathrm{~K}$ to $348.15 \mathrm{~K}$.

\begin{tabular}{|c|c|c|c|c|c|c|c|c|c|}
\hline \multirow{3}{*}{$T / \mathrm{K}$} & \multicolumn{9}{|c|}{$x\left[\mathrm{C}_{8} \mathrm{mim}\right][\mathrm{OAc}]+(1-x) \mathrm{DMSO}, \eta / \mathrm{mPa} \cdot \mathrm{s}$} \\
\hline & \multicolumn{9}{|c|}{$x$} \\
\hline & 1.000 & 0.842 & 0.735 & 0.553 & 0.415 & 0.312 & 0.234 & 0.172 & 0.000 \\
\hline 303.15 & 304.48 & 158.20 & 92.56 & 53.50 & 26.70 & 14.40 & 5.31 & 3.08 & 1.81 \\
\hline 308.15 & 222.12 & 119.37 & 70.25 & 42.71 & 21.92 & 12.12 & 4.61 & 2.70 & 1.67 \\
\hline 313.15 & 165.60 & 91.58 & 55.59 & 33.99 & 18.14 & 10.38 & 3.91 & 2.44 & 1.54 \\
\hline 318.15 & 126.70 & 66.17 & 44.57 & 27.14 & 15.36 & 8.95 & 3.45 & 2.21 & 1.42 \\
\hline 323.15 & 99.22 & 52.28 & 35.52 & 21.81 & 13.12 & 7.82 & 2.93 & 2.03 & 1.31 \\
\hline 328.15 & 77.50 & 41.75 & 29.46 & 17.45 & 11.27 & 6.85 & 2.55 & 1.86 & 1.22 \\
\hline 333.15 & 62.51 & 33.13 & 24.40 & 14.38 & 9.22 & 6.10 & 2.24 & 1.69 & 1.14 \\
\hline 338.15 & 50.11 & 26.94 & 20.52 & 12.11 & 8.27 & 5.42 & 2.02 & 1.59 & 1.07 \\
\hline 343.15 & 41.05 & 22.15 & 17.57 & 10.02 & 7.42 & 4.88 & 1.78 & 1.48 & 1.00 \\
\hline 348.15 & 33.87 & 18.29 & 14.91 & 8.38 & 6.79 & 4.41 & 1.61 & 1.41 & 0.94 \\
\hline
\end{tabular}

The relative combined standard uncertainty $\left(u_{\mathrm{c}, \mathrm{r}}\right)$ is $u_{\mathrm{c}, \mathrm{r}}(\eta)=0.06$.

parameters of $C_{0}, C_{1}, C_{2}$, and $C_{3}$ are fitted by the experimental densities.

Table S4 lists the fit parameters for (7). The calculated density data of the three mixtures are compared with the experiment values. The AARD is $0.11 \%$ for IL with DMSO, $0.20 \%$ for IL with DMA, and $0.22 \%$ for IL with DMF.

3.2. Experimental Viscosity Data and the Effects of Solvents on IL Viscosity. In general, the viscosity can be correlated by the Vogel-Fulcher-Tammann (VFT) equation [46]:

$$
\eta=\eta_{0} \exp \left[\frac{B}{\left(T-T_{0}\right)}\right]
$$

where $\eta$ (mPa.s) is the viscosity; the parameters of $\eta_{0}$ $(\mathrm{mPa} \cdot \mathrm{s}), B(\mathrm{~K})$, and $T_{0}(\mathrm{~K})$ are fitted using the experiment data; $T(\mathrm{~K})$ is the measurement temperature.

Table 6 gives the fit parameters for (8) and AARD. In Figures S7-S9, AARD is $1.96 \%$ for DMSO [14, 24, 25], $1.49 \%$ for DMA [28, 30, 31, 34], and 1.28\% for DMF [14, 20, 38, 47]. It is observed that the deviations between the literature values and the experiment data are desirable. Therefore, the experimental viscosity data of IL with organic solvents are determined and given in Tables 7-9.

Figure 6 and Figures S10-S12 give the experimental viscosity data as a function of IL mole fraction. The viscosity of $\left[\mathrm{C}_{8} \mathrm{mim}\right][\mathrm{OAc}]$ is $304.48 \mathrm{mPa}$ at $303.15 \mathrm{~K}$, while the value decreases to $33.87 \mathrm{mPa}$ at $348.15 \mathrm{~K}$. The IL viscosity is 
TABLE 8: Experimental viscosities of [C8mim] [OAc] with organic solvent of DMA at atmospheric pressure $(0.0967 \pm 0.0020)$ MPa from $303.15 \mathrm{~K}$ to $348.15 \mathrm{~K}$.

\begin{tabular}{|c|c|c|c|c|c|c|c|c|c|}
\hline \multirow{3}{*}{$T / \mathrm{K}$} & \multicolumn{9}{|c|}{$x\left[\mathrm{C}_{8} \mathrm{mim}\right][\mathrm{OAc}]+(1-x) \mathrm{DMA}, \eta / \mathrm{mPa} \cdot \mathrm{s}$} \\
\hline & \multicolumn{9}{|c|}{$x$} \\
\hline & 1.000 & 0.861 & 0.751 & 0.581 & 0.445 & 0.343 & 0.257 & 0.187 & 0.000 \\
\hline 303.15 & 304.48 & 150.44 & 84.15 & 51.38 & 26.85 & 12.55 & 5.05 & 2.46 & 0.88 \\
\hline 308.15 & 222.12 & 113.66 & 65.89 & 40.02 & 22.38 & 10.63 & 4.56 & 2.26 & 0.83 \\
\hline 313.15 & 165.60 & 85.15 & 50.60 & 32.79 & 18.96 & 9.28 & 3.98 & 2.07 & 0.78 \\
\hline 318.15 & 126.70 & 66.05 & 41.17 & 27.01 & 15.84 & 7.94 & 3.57 & 1.91 & 0.74 \\
\hline 323.15 & 99.22 & 50.67 & 33.31 & 22.98 & 13.31 & 6.94 & 3.22 & 1.77 & 0.69 \\
\hline 328.15 & 77.50 & 39.94 & 27.56 & 18.85 & 11.52 & 6.18 & 2.92 & 1.65 & 0.66 \\
\hline 333.15 & 62.51 & 32.10 & 22.65 & 15.80 & 10.14 & 5.45 & 2.66 & 1.54 & 0.62 \\
\hline 338.15 & 50.11 & 26.22 & 18.75 & 13.82 & 8.99 & 4.82 & 2.45 & 1.45 & 0.60 \\
\hline 343.15 & 41.05 & 20.93 & 15.81 & 11.42 & 8.10 & 4.49 & 2.20 & 1.38 & 0.57 \\
\hline 348.15 & 33.87 & 17.45 & 13.78 & 10.44 & 7.40 & 4.13 & 2.02 & 1.31 & 0.54 \\
\hline
\end{tabular}

The relative combined standard uncertainty $\left(u_{\mathrm{c}, \mathrm{r}}\right)$ is $u_{\mathrm{c}, \mathrm{r}}(\eta)=0.06$.

TABLE 9: Experimental viscosities of [C8mim] [OAc] with organic solvent of DMF at atmospheric pressure $(0.0967 \pm 0.0020) \mathrm{MPa}$ from $303.15 \mathrm{~K}$ to $348.15 \mathrm{~K}$.

\begin{tabular}{|c|c|c|c|c|c|c|c|c|c|}
\hline \multirow{3}{*}{$T / K$} & \multicolumn{9}{|c|}{$x\left[\mathrm{C}_{8} \mathrm{mim}\right][\mathrm{OAc}]+(1-x) \mathrm{DMF}, \eta / \mathrm{mPa} \cdot \mathrm{s}$} \\
\hline & \multicolumn{9}{|c|}{$x$} \\
\hline & 1.000 & 0.842 & 0.723 & 0.530 & 0.407 & 0.299 & 0.224 & 0.160 & 0.000 \\
\hline 303.15 & 304.48 & 154.05 & 79.62 & 42.01 & 20.19 & 11.07 & 3.15 & 2.09 & 0.78 \\
\hline 308.15 & 222.12 & 117.48 & 62.38 & 34.41 & 16.69 & 9.60 & 2.85 & 1.93 & 0.72 \\
\hline 313.15 & 165.60 & 90.95 & 48.63 & 28.49 & 14.26 & 8.42 & 2.59 & 1.79 & 0.68 \\
\hline 318.15 & 126.70 & 71.44 & 38.34 & 23.99 & 12.15 & 7.35 & 2.38 & 1.66 & 0.65 \\
\hline 323.15 & 99.22 & 57.67 & 31.45 & 20.36 & 10.46 & 6.49 & 2.18 & 1.54 & 0.62 \\
\hline 328.15 & 77.50 & 46.09 & 25.35 & 17.43 & 9.07 & 5.83 & 2.08 & 1.45 & 0.59 \\
\hline 333.15 & 62.51 & 37.80 & 20.38 & 15.00 & 7.95 & 5.23 & 1.93 & 1.34 & 0.56 \\
\hline 338.15 & 50.11 & 31.33 & 17.83 & 13.02 & 7.05 & 4.68 & 1.74 & 1.27 & 0.54 \\
\hline 343.15 & 41.05 & 26.66 & 14.99 & 11.47 & 6.24 & 4.26 & 1.63 & 1.20 & 0.51 \\
\hline 348.15 & 33.87 & 21.93 & 13.38 & 10.03 & 5.56 & 3.87 & 1.56 & 1.14 & 0.49 \\
\hline
\end{tabular}

The relative combined standard uncertainty $\left(u_{\mathrm{c}, \mathrm{r}}\right)$ is $u_{\mathrm{c}, \mathrm{r}}(\eta)=0.06$.

TABLe 10: The parameters for the hard-sphere theory.

\begin{tabular}{|c|c|c|c|c|c|}
\hline IL/solvent & $a \times 10^{5}$ & $b \times 10^{3}$ & $R_{\eta}$ & AARD & $\mathrm{MD}$ \\
\hline$[\mathrm{C} 8 \mathrm{mim}][\mathrm{OAc}]$ & 19.001 & 10.472 & 1.204 & 0.38 & 0.71 \\
\hline DMSO & 3.644 & 4.340 & 1.549 & 0.11 & 0.28 \\
\hline DMA & 5.271 & 3.266 & 1.263 & 0.16 & 0.32 \\
\hline DMF & 2.333 & 6.984 & 2.604 & 0.27 & 0.72 \\
\hline
\end{tabular}

TABLE 11: The parameters k12 of the hard-sphere theory for the binary mixture.

\begin{tabular}{lcc}
\hline Mixture & $k_{12}$ & AARD \\
\hline \multirow{2}{*}{ IL-DMSO } & 0 & 20.6 \\
& 0.502 & 19.7 \\
\hline \multirow{2}{*}{ IL-DMA } & 0 & 21.2 \\
& 0.942 & 15.6 \\
\hline \multirow{2}{*}{ IL-DMF } & 0 & 25.9 \\
& 1.109 & 16.8 \\
\hline
\end{tabular}

clearly affected by the temperature. The hydrogen bond is proposed as the main factor for governing the interaction of IL viscosity. The high temperature will dramatically weaken the hydrogen-bond intensity and IL viscosity decreases accordingly [40].

Regarding the binary mixture, for instance, at $303.15 \mathrm{~K}$, the viscosity of $\left[\mathrm{C}_{8} \mathrm{mim}\right][\mathrm{OAc}]$ with DMSO drops from $304.48 \mathrm{mPa} \cdot \mathrm{s}$ to $158.20 \mathrm{mPas}$ when the mole fraction of solvent increases from 0 to 0.158 (the mass fraction is 0.05 ); the viscosity decreases to $92.56 \mathrm{mPa}$ s when the mole fraction of solvent increases to 0.265 (the mass fraction is 0.10 ); the viscosity decreases to $53.50 \mathrm{mPa}$ s when the mole fraction of solvent increases to 0.447 (the mass fraction is 0.20 ). It is concluded that a small quantity of the solvent has a great effect on lowering the IL high viscosity. The similar results are observed for IL with DMA or DMF. As shown in Figure 6, there are no significant discrepancies for the effects of the studied solvents on lowering the ionic liquid viscosity. 


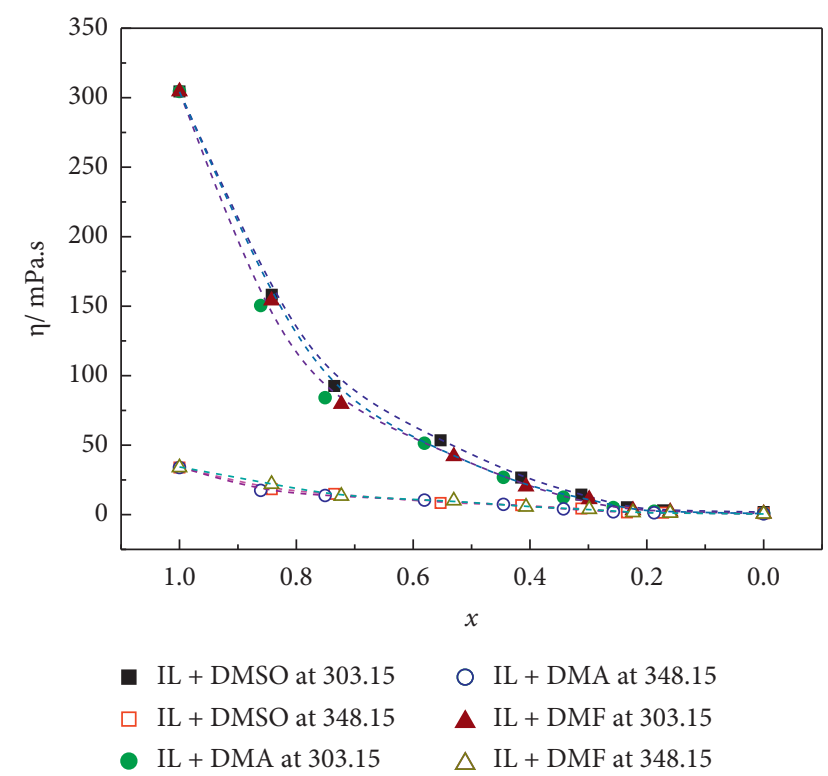

FIgURE 6: Experimental viscosity data of [C8mim][OAc] with solvents as a function of ionic liquid mole fraction at normal pressure.

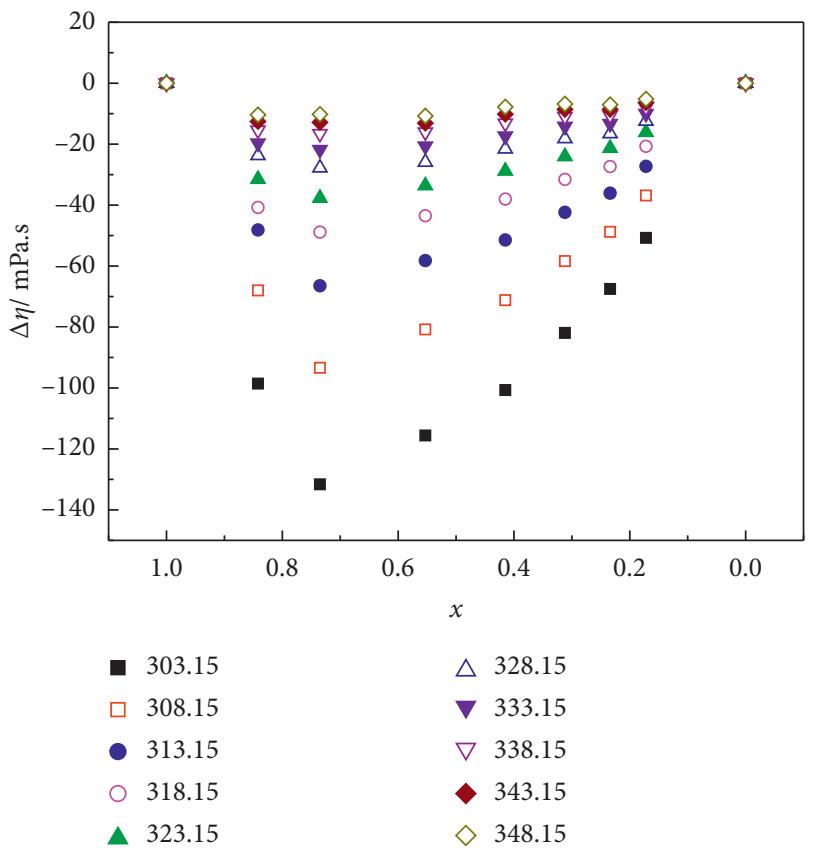

FIgURE 7: The viscosity deviation for the binary mixture of [C8mim] $[\mathrm{OAc}]$ with solvent of DMSO as a function of ionic liquid mole fraction at atmospheric pressure.

According to the experimental data, the energy barrier $E_{\eta}$ is introduced and it is a potential field that can be used to either localize or regulate the transfer of charged particles, for example, electrons [48]. Therefore, the higher the energy

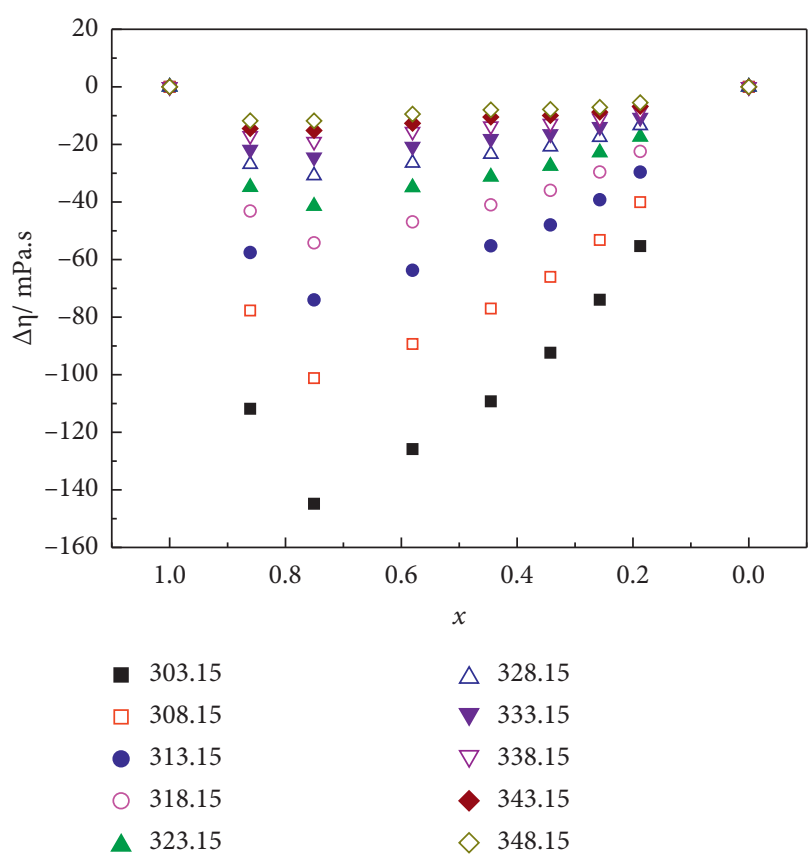

FIgURE 8: The viscosity deviation for the binary mixture of [C8mim] [OAc] with solvent of DMA as a function of ionic liquid mole fraction at atmospheric pressure.

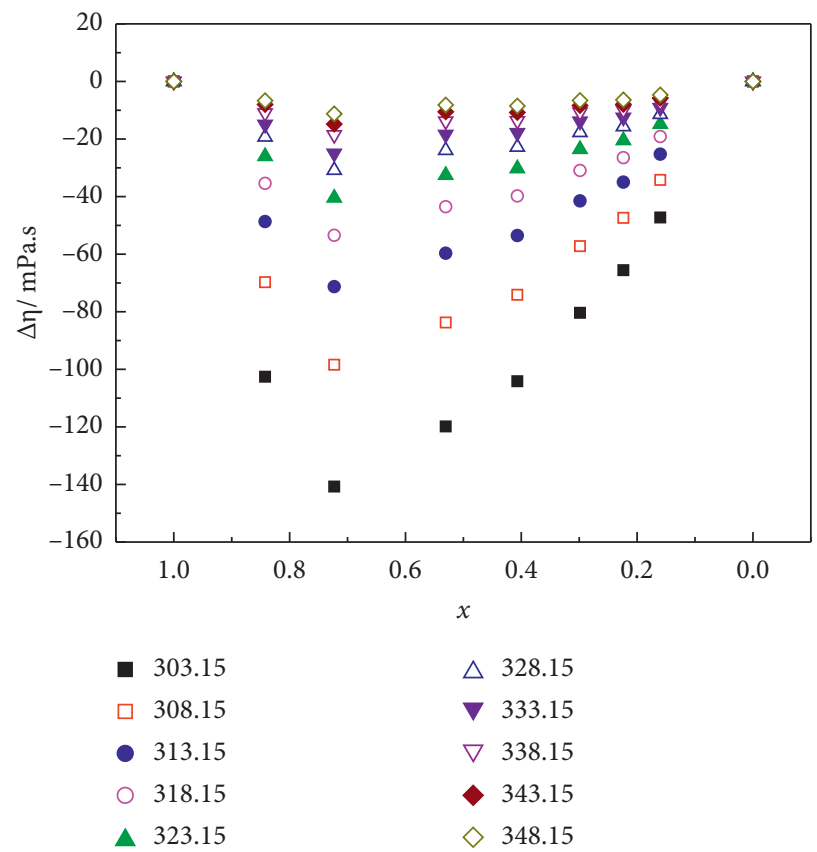

FIgURE 9: The viscosity deviation for the binary mixture of [C8mim] [OAc] with solvent of DMF as a function of ionic liquid mole fraction at atmospheric pressure.

barrier value is, the more difficult it is for the ions to move or be regulated, and the energy barrier $E_{\eta}$ is calculated by [46]

$$
E_{\eta}=R \times \frac{\partial \ln \eta}{\partial(1 / T)}=R\left(\frac{B}{\left.\left(\left(T_{0}^{2} / T^{2}\right)-\left(2 T_{0} / T\right)+1\right)\right)},\right.
$$




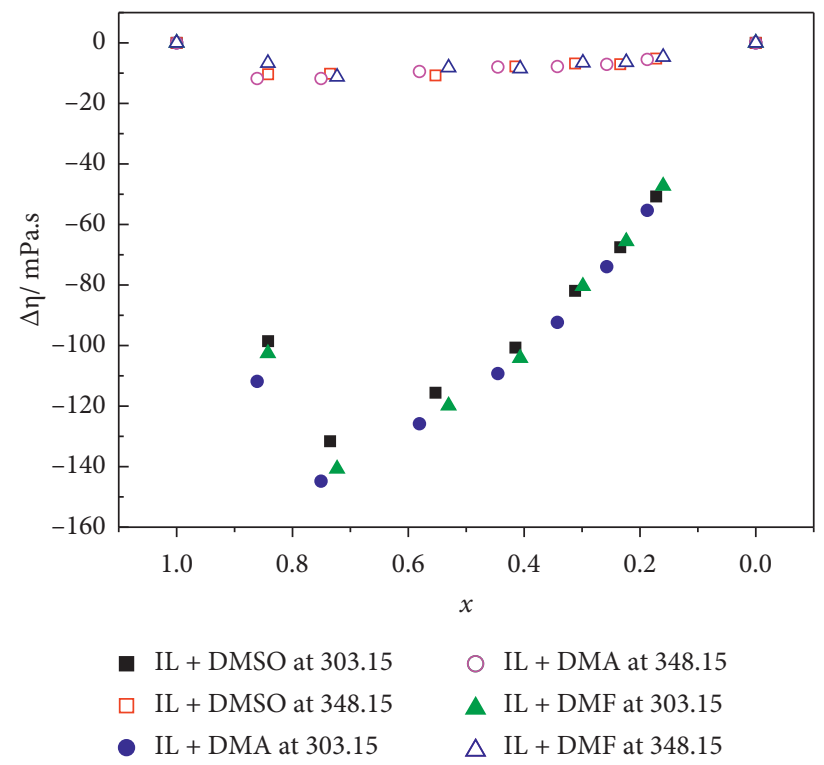

Figure 10: The viscosity deviation for the binary mixture of [C8mim][OAc] with solvents as a function of ionic liquid mole fraction at atmospheric pressure.

where $R$ is the ideal gas constant and it is approximately $8.314 \mathrm{JK}^{-1} \mathrm{~mol}^{-1} ; \eta(\mathrm{mPa} \cdot \mathrm{s})$ is the viscosity; $B(\mathrm{~K})$ and $T_{0}(\mathrm{~K})$ are obtained from (8).

Table 6 gives the energy barrier at $303.15 \mathrm{~K}$. The value of the energy barrier decreases with the increase of the solvent content in the binary mixture that is consistent with the phenomenon of the decrease for the binary mixture viscosity when the solvent content in the mixture increases.

Based on the experiment data, the viscosity deviation, $\Delta \eta$, is calculated to analyze the effect of the solvent on IL viscosity according to the following equation:

$$
\Delta \eta=\eta-\sum x_{i} \eta_{i}
$$

where $\eta$ and $x$ are the viscosity and mole fraction, respectively. The subscript of " $i$ " means the property of pure substance $i$. The relative combined standard uncertainty of the viscosity deviation is 0.14 .

Figures 7-10 give the viscosity deviation as a function of ionic liquid mole fraction at atmospheric pressure. In the studied temperatures, the deviations are all negative and the absolute values increase with the decrease of temperature because IL viscosity at high temperature is at the same order of magnitude with that of the solvent and, then, the viscosity deviations at high temperature become smaller. The curves are asymmetric and the minimum values are detected at the concentrated area.

In the previous studies, spectra of IL presented that a delocalization of the electrons in ionic acetate anion and the interactions with IL cation were observed; moreover, the comparatively weak $\mathrm{C}-\mathrm{H}$ stretching was detected, whereas a broad band corresponding to the intermolecular $\mathrm{O}-\mathrm{H}$ vibrations caused by the $\mathrm{H}$-bond was determined [49]. It is therefore reasonable to infer that there are possible $\mathrm{H}$-bond intermolecular interactions between the $\mathrm{O}-\mathrm{H}$ vibrations in IL cation with $S=O$ in DMSO, $C=O$ in DMA, and DMF.
Furthermore, the hard-sphere theory is used to study the binary viscosity. The reduced viscosity of rough hard-sphere $\eta_{\mathrm{RHS}}^{*}$ is related to the reduced viscosity of smooth hardsphere $\eta_{\mathrm{SHS}}^{*}$ through a proportionally constant $R_{\eta}$ [50-52]:

$$
\eta_{\mathrm{RHS}}^{*}=R_{\eta} \eta_{\mathrm{SHS}}^{*}
$$

The reduced viscosity of rough hard sphere is calculated as follows:

$$
\eta_{\mathrm{RHS}}^{*}=6.035 \times 10^{8} \times(M R T)^{-0.5} \eta V^{(2 / 3)},
$$

where $M\left(\mathrm{~kg} \cdot \mathrm{mol}^{-1}\right)$ is the molecular weight, $R$ is the universal gas constant and it is $8.3141 \mathrm{~J} \mathrm{~mol}^{-1} \mathrm{~K}^{-1}, T(\mathrm{~K})$ is the temperature, $\eta(\mathrm{Pa} \cdot \mathrm{s})$ is the viscosity, and $V\left(\mathrm{~m}^{3} \cdot \mathrm{mol}^{-1}\right)$ is the molar volume.

The reduced viscosity of smooth hard sphere is expressed as follows:

$$
\log _{10}\left(\eta_{\mathrm{SHS}}^{*}\right)=\log _{10}\left(\frac{\eta_{\mathrm{RHS}}^{*}}{R_{\eta}}\right)=\sum_{i=0}^{7} a_{\eta i}\left(\frac{V}{V_{0}}\right)^{-i} .
$$

$V / V_{0}$ is defined as the reduced molar volume $V_{\mathrm{r}}$ and $V_{0}$ $\left(\mathrm{m}^{3} \cdot \mathrm{mol}^{-1}\right)$ is a characteristic molar volume. Ciotta et al. extended the expression to high-viscosity hydrocarbons and the coefficients $a_{\eta \mathrm{i}}$ are $0,5.14262,-35.5878,192.05015$, $-573.37246,957.41955,-833.36825$, and 299.40932 [53]. The characteristic molar volume $V_{0}$ is proposed as follows [52]:

$$
V_{0}=a+b / T \text {, }
$$

where the parameters of $a, b$, and $R_{\eta}$ are fitted by the viscosity data in this work. Table 10 gives the fit parameters, AARD, and the maximum absolute relative deviation (MD).

For the binary mixture, the mixing rule for the binary mixture of IL with water proposed by Teja et al. is employed for IL with solvents [52]: 


$$
\begin{aligned}
\log \left(\eta_{\text {mix }}\right)= & x_{1} \log \left(\eta_{1}\right)+x_{2} \log \left(\eta_{2}\right) \\
& +2 x_{1} x_{2} k_{12}\left(\frac{M_{1} M_{2}}{M_{\text {mix }}}\right)^{(1 / 2)}
\end{aligned}
$$

where $k_{12}$ is a binary interaction parameter. Table 11 presents the parameter $k_{12}$ and AARD. The deviations are large for the binary mixture. The deviations are larger than $20 \%$ without the adjustable parameter of $k_{12}$, but they are reduced to less than $20 \%$ when $k_{12}$ is used. Teja et al. reported the deviations in the range of $7.10 \%-16.37 \%$ using the mixing rule for the viscosity prediction of water with IL [52]. The addition of solvent significantly lowers the IL viscosity, and the above analysis indicates that $\mathrm{H}$-bond intermolecular interactions occur between ionic liquid and solvents; therefore, the mixing rules are required for further study and improvement.

\section{Conclusions}

In this work, the thermophysical properties of the densities and viscosities for $\left[\mathrm{C}_{8} \mathrm{mim}\right][\mathrm{OAc}]$ with the organic solvents (i.e., DMSO, DMA, and DMF) were studied at normal pressure in the temperature ranges from $303.15 \mathrm{~K}$ to $348.15 \mathrm{~K}$. The excess molar volume was calculated and the values are negative under the studied temperatures, indicating that the volumes of binary mixtures become smaller than the ideal ones and there should be interactions between the IL and the solvents. Regarding the viscosity, a small proportion of solvent would lower ionic liquid viscosity. Among the three solvents, there are no apparent distinctions on lowering IL viscosity. Summarily, the small deviations for the density from the ideality are observed, while larger deviations for the viscosity are detected. The rough hardsphere model works well to reproduce the viscosity behavior of the pure substances, while the mixing rules for the binary mixture merit further study.

\section{Data Availability}

The data are available in the Supplementary Material: the parameters fitted in this work for (2) and (5); the deviation for solvents between the literature density/viscosity and the experimental data in this work; experimental density/viscosity data of ionic liquid with solvents as a function of the temperature or IL mole fraction.

\section{Conflicts of Interest}

The authors declare that they have no conflicts of interest.

\section{Acknowledgments}

The work was supported by the National Natural Science Foundation of China (no. 51976166).

\section{Supplementary Materials}

The following are provided: chemical structure and physical properties of IL; the parameters fitted in this work for (2),
(5), and (7); the deviation for solvents between the literature density/viscosity and the experimental data in this work; experimental density/viscosity data of ionic liquid with solvents as a function of the temperature or IL mole fraction. (Supplementary Materials)

\section{References}

[1] H. Abushammala and J. Mao, "A review on the partial and complete dissolution and fractionation of wood and lignocelluloses using imidazolium ionic liquids," Polymers, vol. 12, no. 1, p. 195, 2020.

[2] H. Zhao and G. A. Baker, "Ionic liquids and deep eutectic solvents for biodiesel synthesis: a review," Journal of Chemical Technology \& Biotechnology, vol. 88, no. 1, pp. 3-12, 2013.

[3] M. M. Hossain, A. Rawal, and L. Aldous, "Aprotic vs protic ionic liquids for lignocellulosic biomass pretreatment: anion effects, enzymatic hydrolysis, solid-state NMR, distillation, and recycle," ACS Sustainable Chemistry \& Engineering, vol. 7, pp. 11928-11936, 2019.

[4] A. M. Socha, R. Parthasarathi, J. Shi et al., "Efficient biomass pretreatment using ionic liquids derived from lignin and hemicellulose," Proceedings of the National Academy of Sciences, vol. 111, no. 35, pp. E3587-E3595, 2014.

[5] Y. Yang, H. Fan, Q. Meng, Z. Zhang, G. Yang, and B. Han, "Ionic liquid [OMIm][OAc] directly inducing oxidation cleavage of the $\beta-\mathrm{O}-4$ bond of lignin model compounds," Chemical Communications, vol. 53, no. 63, pp. 8850-8853, 2017.

[6] Y. Wang, L. Wei, K. Li et al., "Lignin dissolution in dialkylimidazolium-based ionic liquid-water mixtures," Bioresource Technology, vol. 170, pp. 499-505, 2014.

[7] J. Zhang, L. Xu, J. Yu et al., "Understanding cellulose dissolution: effect of the cation and anion structure of ionic liquids on the solubility of cellulose," Science China Chemistry, vol. 59, no. 11, pp. 1421-1429, 2016.

[8] S. Wang, W. Zhao, T. S. Lee et al., "Dimethyl sulfoxide assisted ionic liquid pretreatment of switchgrass for isoprenol production," ACS Sustainable Chemistry \& Engineering, vol. 6, no. 3, pp. 4354-4361, 2018.

[9] M. Gericke, T. Liebert, O. A. E. Seoud, and T. Heinze, "Tailored media for homogeneous cellulose chemistry: ionic liquid/Co-solvent mixtures," Macromolecular Materials and Engineering, vol. 296, no. 6, pp. 483-493, 2011.

[10] S. Fendt, S. Padmanabhan, H. W. Blanch, and J. M. Prausnitz, "Viscosities of acetate or chloride-based ionic liquids and some of their mixtures with water or other common solvents," Journal of Chemical \& Engineering Data, vol. 56, no. 1, pp. 31-34, 2011.

[11] S. Guo, F. Chen, L. Liu et al., "Effects of the water content on the transport properties of ionic liquids," Industrial \& Engineering Chemistry Research, vol. 58, no. 42, pp. 19661-19669, 2019.

[12] O. Iulian and O. Ciocirlan, "Volumetric properties of binary mixtures of two 1-alkyl-3-methylimidazolium tetrafluoroborate ionic liquids with molecular solvents," Journal of Chemical \& Engineering Data, vol. 57, no. 10, pp. 2640-2646, 2012.

[13] X.-H. Fan, Y.-P. Chen, and C.-S. Su, "Density and viscosity measurements for binary mixtures of 1-Ethyl-3-methylimidazolium tetrafluoroborate ([Emim][BF4]) with dimethylacetamide, dimethylformamide, and dimethyl sulfoxide," Journal of Chemical \& Engineering Data, vol. 61, no. 2, pp. 920-927, 2016. 
[14] C. Yang, G. He, Y. He, and P. Ma, "Densities and viscosities ofN,N-dimethylformamide $+\mathrm{N}$-Methyl-2-pyrrolidinone and + dimethyl sulfoxide in the temperature range (303.15 to 353.15) K," Journal of Chemical \& Engineering Data, vol. 53, no. 7, pp. 1639-1642, 2008.

[15] O. Ciocirlan, "Viscosities of 1-Hexyl-3-methylimidazolium tetrafluoroborate and its binary mixtures with dimethyl sulfoxide and acetonitrile," Journal of Chemical \& Engineering Data, vol. 63, no. 11, pp. 4205-4214, 2018.

[16] H. Saba, X. Zhu, Y. Chen, and Y. Zhang, "Determination of physical properties for the mixtures of [BMIM]Cl with different organic solvents," Chinese Journal of Chemical Engineering, vol. 23, no. 5, pp. 804-811, 2015.

[17] D. Papamatthaiakis, F. Aroni, and V. Havredaki, "Isentropic compressibilities of (amide+water) mixtures: a comparative study," The Journal of Chemical Thermodynamics, vol. 40, no. 1, pp. 107-118, 2008.

[18] S. L. Oswal and N. B. Patel, "Speed of sound, isentropic compressibility, viscosity, and excess volume of binary mixtures. 2. Alkanenitriles + dimethylformamide, + dimethylacetamide, and + dimethyl sulfoxide," Journal of Chemical \& Engineering Data, vol. 40, no. 4, pp. 845-849, 1995.

[19] M. Almasi, "Thermodynamic properties of binary mixtures containing N,N-dimethylacetamide + 2-alkanol: experimental data and modeling," Journal of Chemical \& Engineering Data, vol. 59, no. 2, pp. 275-281, 2014.

[20] J. M. Bernal-García, A. Guzmán-López, A. Cabrales-Torres, A. Estrada-Baltazar, and G. A. Iglesias-Silva, "Densities and viscosities of (N,N-dimethylformamide + water) at atmospheric pressure from (283.15 to 353.15) K," Journal of Chemical \& Engineering Data, vol. 53, no. 4, pp. 1024-1027, 2008.

[21] A. Marchetti, C. Preti, M. Tagliazucchi, L. Tassi, and G. Tosi, "The N,N-dimethylformamide/ethane-1,2-diol solvent system. Density, viscosity, and excess molar volume at various temperatures," Journal of Chemical \& Engineering Data, vol. 36, no. 4, pp. 360-365, 1991.

[22] A. N. Campbell, "The density and vapour pressure of dimethylsulfoxide at various temperatures and the (hypothetical) critical density," Canadian Journal of Chemistry, vol. 57, no. 6, pp. 705-707, 1979.

[23] G. I. Egorov, D. M. Makarov, and A. M. Kolker, "Densities and volumetric properties of ethylene glycol + dimethylsulfoxide mixtures at temperatures of (278.15 to 323.15$) \mathrm{K}$ and pressures of (0.1 to 100) MPa," Journal of Chemical \& Engineering Data, vol. 55, no. 9, pp. 3481-3488, 2010.

[24] J. F. Casteel and P. G. Sears, "Dielectric constants, viscosities, and related physical properties of 10 liquid sulfoxides and sulfones at several temperatures," Journal of Chemical \& Engineering Data, vol. 19, no. 3, pp. 196-200, 1974.

[25] O. Ciocirlan and O. Iulian, "Properties of pure 1-Butyl-2,3dimethylimidazolium tetrafluoroborate ionic liquid and its binary mixtures with dimethyl sulfoxide and acetonitrile," Journal of Chemical \& Engineering Data, vol. 57, no. 11, pp. 3142-3148, 2012.

[26] X. Wang, F. Yang, Y. Gao, and Z. Liu, "Volumetric properties of binary mixtures of dimethyl sulfoxide with amines from (293.15 to 363.15)K," The Journal of Chemical Thermodynamics, vol. 57, pp. 145-151, 2013.

[27] P. García-Giménez, J. F. Martínez-López, S. T. Blanco, I. Velasco, and S. Otín, "Densities and isothermal compressibilities at pressures up to $20 \mathrm{MPa}$ of the SystemsN,N-dimethylformamide orN,N-dimethylacetamide + 1-chloroalkane,"
Journal of Chemical \& Engineering Data, vol. 52, no. 5, pp. 1693-1699, 2007.

[28] M. Watanabe, D. Kodama, T. Makino, and M. Kanakubo, "Density, viscosity, and electrical conductivity of protic amidium bis (trifluoromethanesulfonyl) amide ionic liquids," Journal of Chemical \& Engineering Data, vol. 61, no. 12, pp. 4215-4221, 2016.

[29] J. Krakowiak, H. Koziel, and W. Grzybkowski, "Apparent molar volumes of divalent transition metal perchlorates and chlorides in N,N-dimethylacetamide," Journal of Molecular Liquids, vol. 118, no. 1-3, pp. 57-65, 2005.

[30] H. Zarei, S. A. Golroudbari, and M. Behroozi, "Experimental studies on volumetric and viscometric properties of binary and ternary mixtures of N,N-dimethylacetamide, N-methylformamide and propane-1,2-diol at different temperatures," Journal of Molecular Liquids, vol. 187, pp. 260-265, 2013.

[31] A. K. Nain, "Densities, ultrasonic speeds, viscosities and excess properties of binary mixtures of methyl methacrylate with $\mathrm{N}, \mathrm{N}$-dimethylformamide and N,N-dimethylacetamide at different temperatures," The Journal of Chemical Thermodynamics, vol. 60, pp. 105-116, 2013.

[32] A. Płaczek, H. Koziel, and W. Grzybkowski, “Apparent molar compressibilities and volumes of some 1,1-electrolytes in N,N-dimethylacetamide and N,N-dimethylformamide," Journal of Chemical \& Engineering Data, vol. 52, pp. 699-706, 2007.

[33] D. Warmińska, A. Fuchs, and D. Lundberg, “Apparent molar volumes and compressibilities of lanthanum, gadolinium, lutetium and sodium trifluoromethanesulfonates in N,Ndimethylformamide and N,N-dimethylacetamide," The Journal of Chemical Thermodynamics, vol. 58, pp. 46-54, 2013.

[34] J.-Y. Wu, Y.-P. Chen, and C.-S. Su, "Density and viscosity of ionic liquid binary mixtures of 1-n-Butyl-3-methylimidazolium tetrafluoroborate with acetonitrile, N,N-dimethylacetamide, methanol, and N-Methyl-2-pyrrolidone," Journal of Solution Chemistry, vol. 44, no. 3-4, pp. 395-412, 2015.

[35] A. J. Easteal and L. A. Woolf, "Self-diffusion and volumetric measurements for N-methylformamide and N,N-dimethylformamide at temperatures from 240 to $313 \mathrm{~K}$ and pressures up to $300 \mathrm{MPa}$," Journal of the Chemical Society, Faraday Transactions 1: Physical Chemistry in Condensed Phases, vol. 81, no. 11, pp. 2821-2833, 1985.

[36] P. Venkatesu, M. J. Lee, and H. M. Lin, "Volumetric properties of (N,N-dimethylformamide+aliphatic diethers) at temperatures ranging from (298.15 to 358.15$) \mathrm{K}$," The Journal of Chemical Thermodynamics, vol. 37, no. 9, pp. 996-1002, 2005.

[37] H. Kahl, T. Wadewitz, and J. Winkelmann, "Surface tension of pure liquids and binary liquid mixtures," Journal of Chemical \& Engineering Data, vol. 48, no. 3, pp. 580-586, 2003.

[38] C. Yang, G. Wei, and Y. Li, "Densities and viscosities ofN,Ndimethylformamide + formic acid, and + acetic acid in the temperature range from (303.15 to 353.15) K," Journal of Chemical \& Engineering Data, vol. 53, no. 5, pp. 1211-1215, 2008.

[39] J. J. Wessing and J. Brillo, "Density, molar volume, and surface tension of liquid Al-Ti," Metallurgical and Materials Transactions A, vol. 48, no. 2, pp. 868-882, 2017.

[40] H. Rodríguez and J. F. Brennecke, "Temperature and composition dependence of the density and viscosity of binary mixtures of water + ionic liquid," Journal of Chemical \& Engineering Data, vol. 51, no. 6, pp. 2145-2155, 2006. 
[41] F. Amararene, P. Balz, C. Bouallou et al., "Densities of water + diethanolamine + methanol and water $+\mathrm{N}$-methyldiethanolamine + methanol at temperatures ranging from (283.15 to 353.15) K," Journal of Chemical \& Engineering Data, vol. 48, no. 6, pp. 1565-1570, 2003.

[42] O. Redlich and A. T. Kister, "Algebraic representation of thermodynamic properties and the classification of solutions," Industrial \& Engineering Chemistry, vol. 40, no. 2, pp. 345-348, 1948.

[43] F. Yang, X. Wang, Q. Chen, and H. Tan, "Improvement of the properties of 1-ethyl-3-methylimidazolium acetate using organic solvents for biofuel process," Journal of Molecular Liquids, vol. 284, pp. 82-91, 2019.

[44] L. d. P. Nisa, M. Mugang, M. D. Bermejo, J. J. Segovia Puras, and E. Pérez, "Density and melting points for the binary mixtures dimethyl sulfoxide (DMSO) + 1-Ethyl-3-methylimidazolium acetate and DMSO + choline acetate," Journal of Chemical \& Engineering Data, vol. 64, no. 7, pp. 2923-2928, 2019.

[45] A. Apelblat, "A new two-parameter equation for correlation and prediction of densities as a function of concentration and temperature in binary aqueous solutions," Journal of Molecular Liquids, vol. 219, pp. 313-331, 2016.

[46] H. F. D. Almeida, J. N. Canongia Lopes, L. P. N. Rebelo, J. A. P. Coutinho, M. G. Freire, and I. M. Marrucho, "Densities and viscosities of mixtures of two ionic liquids containing a common cation," Journal of Chemical \& Engineering Data, vol. 61, no. 8, pp. 2828-2843, 2016.

[47] M. Cocchi, M. Manfredini, D. Manzini et al., "Viscosimetric properties and internal structure of $\mathrm{N}, \mathrm{N}$-dimethylformamide + 1,2-dimethoxyethane binary mixtures," Journal of Molecular Liquids, vol. 102, no. 1-3, pp. 309-345, 2003.

[48] V. V. Zhirnov and R. K. Cavin, "Chapter 2-basic physics of ICT," in Microsystems for Bioelectronics, V. V. Zhirnov and R. K. Cavin, Eds., pp. 19-49, William Andrew Publishing, Oxford, England, 2nd edition, 2015.

[49] J. Kiefer, K. Obert, A. Bösmann, T. Seeger, P. Wasserscheid, and A. Leipertz, "Quantitative analysis of alpha-D-glucose in an ionic liquid by using infrared spectroscopy," ChemPhysChem, vol. 9, no. 9, pp. 1317-1322, 2008.

[50] F. M. Gaciño, M. J. P. Comuñas, J. Fernández, S. K. Mylona, and M. J. Assael, "Correlation and prediction of dense fluid transport coefficients. IX. Ionic liquids," International Journal of Thermophysics, vol. 35, no. 5, pp. 812-829, 2014.

[51] T. Sun and A. S. Teja, "Correlation and prediction of the viscosity and thermal conductivity of dense fluids $\dagger$," Journal of Chemical \& Engineering Data, vol. 54, no. 9, pp. 2527-2531, 2009.

[52] M. Z. Hossain and A. S. Teja, "Correlation and prediction of the transport properties of ionic liquids," International Journal of Thermophysics, vol. 37, p. 9, 2016.

[53] F. Ciotta, J. P. M. Trusler, and V. Vesovic, "Extended hardsphere model for the viscosity of dense fluids," Fluid Phase Equilibria, vol. 363, pp. 239-247, 2014. 